\title{
Patterns of Pacific decadal variability recorded by Indian Ocean corals
}

\author{
Traute Crueger $\cdot$ Jens Zinke $\cdot$ Miriam Pfeiffer
}

Received: 19 February 2007/ Accepted: 4 May 2008/Published online: 12 June 2008

(C) The Author(s) 2008

\begin{abstract}
We investigate Pacific Decadal Oscillation (PDO) signals recorded by two bimonthly resolved coral $\delta^{18} \mathrm{O}$ series from La Réunion and Ifaty (West Madagascar), Indian Ocean from 1882 to 1993 . To isolate the main PDO frequencies, we apply a band pass filter to the time series passing only periodicities from 16 to 28 years. We investigate the covariance patterns of the coral time series with sea surface temperature (SST) and sea level pressure (SLP) of the Indian and Pacific Oceans. In addition, the empirical orthogonal functions of the filtered SST and SLP fields (single and coupled) are related to the filtered coral times series. The covariance maps show the typical PDO pattern for SST and SLP, confirming the coupling between the Indian and Pacific Oceans. Both corals show the strongest signal in boreal summer. The La Réunion (Ifaty) coral better records SST (SLP) than SLP (SST) pattern variability. We suggest that the filtered La Réunion coral $\delta^{18} \mathrm{O}$ represents $\delta^{18} \mathrm{O}$ of seawater that varies with the South Equatorial Current, which, in turn, is linked with the SST
\end{abstract}

AGU OS06 special issue "Ocean's role in climate change-a paleo perspective".

T. Crueger $(\bowtie)$

Max Planck Institute for Meteorology,

Hamburg, Bundesstrasse 53, 20146 Hamburg, Germany

e-mail: traute.crueger@zmaw.de

URL: http://www.mpimet.mpg.de/institut/mitarbeiter/

cruegertraute/index.html

J. Zinke

Vrije Universiteit Amsterdam, De Boelelaan 1085,

1081 HV Amsterdam, The Netherlands

M. Pfeiffer

Leibniz Institut für Meereswissenschaften, IFM-GEOMAR Kiel,

Wischhofstrasse 1-3, 24148 Kiel, Germany
PDO. The filtered Ifaty coral $\delta^{18} \mathrm{O}$ represents SST and is remotely linked with the SLP PDO variability. A combined coral record of the Ifaty and La Réunion boreal summer $\delta^{18} \mathrm{O}$ series explains about $64 \%$ of the variance of the coupled SST/SLP PDO time series.

Keywords Corals $\cdot \delta^{18} \mathrm{O}$.

Pacific Decadal Oscillation (PDO) - Indian Ocean ·

South Equatorial Current (SEC) .

Mozambique Channel Eddies (MCE) .

Climate reconstruction

\section{Introduction}

The most dominant feature of the climate in the Indian Ocean is the seasonal cycle of the Asian monsoon, mainly influencing the region north of $10^{\circ} \mathrm{S}$. During the southwest monsoon of the boreal summer, the southern hemisphere trade winds cross the Equator and blow into the southern parts of Asia. These winds evaporate water from the Indian Ocean, which subsequently falls as heavy monsoonal rainfall over land, especially in the western parts of India. In contrast to the southwest monsoon, the northeast monsoon blows from the Asian continent in the boreal winter. The seasonal monsoon system leads to maximum precipitation in the area of the Intertropical Convergence Zone (ITCZ) at around $10^{\circ} \mathrm{S}$. Besides this strong seasonal climate feature, there is interannual modulation of the Indian Ocean climate, related to the El Niño/Southern Oscillation (ENSO). The eastern Indian Ocean, which is part of the western Pacific warm pool (WPWP), shows the highest SSTs of the Indian Ocean. This pattern is reversed during the El Niño phase of ENSO, when the WPWP shows anomalously cool SSTs. ENSO co-varies with the transport 
of the Indonesian throughflow and salinity in the West Indian Ocean (Godfrey 1996; Gordon and McClean 1999). Recently it has been suggested that ENSO lags the Indian Ocean SST pattern by a couple of months, leading to the hypotheses that ENSO can be predicted by the SST anomalies of the southeastern Indian Ocean (Dominiak and Terray 2005; Webster et al. 1999; Webster et al. 1998). The strongest interannual signal in the Indian Ocean climate is related to ENSO, however, its teleconnection pattern is modulated by interdecadal climate variability: The Pacific Decadal Oscillation (PDO) modulates the ENSO signal in the Pacific and remotely in the Indian Ocean. Since the PDO is a low-frequency phenomenon, it is not well captured by the relatively short instrumental climate records. The PDO, also called Interdecadal Pacific Oscillation (IPO) or North Pacific Oscillation (NPO), refers to slightly different definitions (for a review see Mantua and Hare 2002). On the one hand the PDO is described as the low-frequency co-variability of Pacific SST and SLP patterns (Kaplan et al. 2000; Minobe 1999, 2000). On the other hand, Barlow et al. (2001) and Nakamura et al. (1997) considered only distinct and independent decadal North Pacific SST modes. Despite the different approaches, the PDO patterns show similar structures, on the whole resembling the ENSO-pattern: in the warm phase positive SST anomalies in the Equatorial Pacific and along the west coasts of the Americas are accompanied by negative SST anomalies especially in the Central North Pacific. This pattern co-varies with a SLP pattern, which is characterized by lower pressure in the North Pacific. In contrast to ENSO which is centered in the central and eastern equatorial Pacific, the main PDO signature is found in the North Pacific/North American region. Therefore, the main impacts of the PDO are found in the North Pacific, where, for example, the salmon production and the air temperature in Northwest America show strong decadal variations (Mantua et al. 1997). The most striking difference between ENSO and PDO are their periodicities. Whereas the period lengths during the last century have been from 15 to 25 years and from 50 to 70 years for the PDO (Mantua and Hare 2002; Mantua et al. 1997; Zhang et al. 1997), ENSO appears between 3 and 7 years. The phenomenon and the underlying physical processes of the PDO are not well known yet. However, owing to the low frequencies of the PDO, its persistence is high. Therefore, climatic information about the PDO potentially improves climatic predictions even from year to year.

One remaining mystery of the PDO is its potential link with decadal climate variability in the Indian Ocean. Allan et al. (1995) investigated the mean SST, SLP and surface wind patterns of four 21-year periods of the twentieth century and found pronounced changes around the Agulhas Current (AC) outflow and also indications of a relationship between these changes and northwest Pacific Ocean SST variability. A similar approach applied by Deser et al. (2004) revealed a strong linkage between SLP, precipitation and SST in the Pacific area. In addition they showed that precipitation in the North Pacific varies with rainfall around Madagascar. Thus they suggested a link between decadal variability in the southwest Indian Ocean and the PDO. Reason and Rouault (2002) suggested a link between ENSO-like decadal variability and South African rainfall. Krishnan and Sugi (2003) specified that the link between SST anomalies in the Indian Ocean and Pacific Ocean is stronger in the PDO than in the ENSO frequency band. Several potential processes involved in the decadal variability of the Indian Ocean have been reported through analysis of coral proxy climate records in Pfeiffer et al. (2004): firstly basin-scale atmosphere/ocean interactions are suggested to modulate the strength of the south Indian Ocean gyre. Furthermore a remote forcing via the Indonesian throughflow is suggested. Finally they suggested that variations in the surface heat fluxes of the Indian Ocean in response to the local wind forcing potentially contribute to this phenomenon.

Because of the lack of sufficiently long instrumental data, paleoclimatic data represent an important tool for the detection of PDO signals beyond the instrumental period. Such signals are found in and around the areas of maximum PDO variability in tree rings and corals (D'Arrigo and Wilson 2006; D'Arrigo et al. 2005; Dunbar et al. 1994). In addition, corals can provide evidence in areas remotely influenced by the PDO, e.g. in the South Pacific, near Rarotonga and Fiji (Linsley et al. 2004). Records of these corals clearly record the twentieth century variations of the PDO and are also in good agreement with a PDO reconstruction derived from North American tree rings. This confirms that the PDO is at least a Pacific-wide phenomenon operating over the past several centuries (Evans et al. 2001). Paleoclimatic evidence for a link between the Indian Ocean and the PDO has not been supplied until now. However, Pfeiffer et al. (2004) performed a spectral analysis of the annual coral $\delta^{18} \mathrm{O}$ from La Réunion, which is investigated in this article. Although they found a spectral peak around 35 years, they did not directly prove a remote link between the spatial patterns of the PDO and the coral from the Indian Ocean. This is the scope of this paper. The aim is to detect the PDO fingerprint in southwest Indian Ocean corals. For that reason we use two bimonthly resolved coral $\delta^{18} \mathrm{O}$ time series, one from Ifaty off the southwest coast of Madagascar (Zinke et al. 2004a, b) and one from La Réunion (Pfeiffer et al. 2004). The spatial patterns are found by the establishment of covariance maps and by empirical orthogonal functions (EOFs) of band-pass filtered data. We confine our investigation to one dominant PDO frequency band reported in the literature, namely 
representing periods between 16 and 28 years (Mantua and Hare 2002).

The paper is structured as follows: After describing the data in "Data", the climatic and oceanic settings of the coral sites are given in "Climatic and oceanic settings of the coral sites", the statistical approach is presented in "Methods". In "Results" we perform the analysis between the coral time series and the SST and SLP fields, respectively. Finally, the results are discussed.

\section{Data}

Corals

In this study, two corals from the southwestern subtropical Indian Ocean are investigated, one from the southwestern coast of Madagascar, the other from La Réunion, $800 \mathrm{~km}$ east of Madagascar (Fig. 1). The Madagascar coral of the species Porites lobata is from the lagoon of Ifaty southwest of Madagascar near Tulear $\left(23^{\circ} \mathrm{S}\right.$ and $\left.43.5^{\circ} \mathrm{E}\right)$ (hereafter IF). The maximum water depth of this lagoon is $12 \mathrm{~m}$ and the lagoon is not influenced by freshwater from rivers or oceanic upwelling. However, the exchange with the open ocean takes place through large passages (Zinke et al.

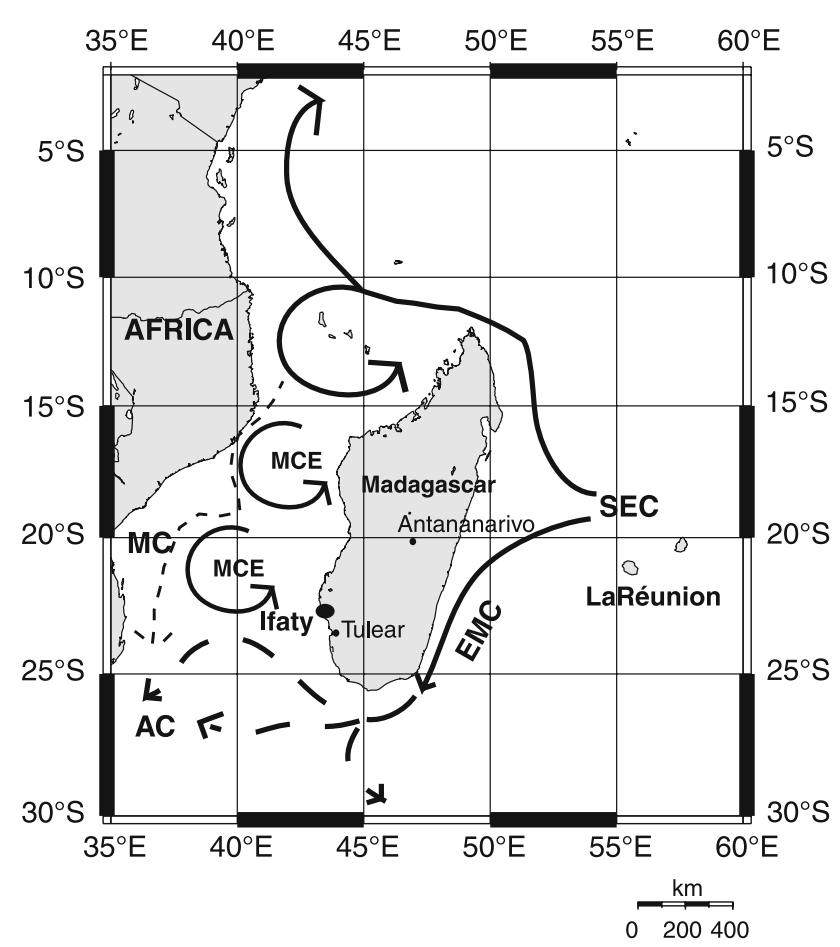

Fig. 1 Coral sites in Ifaty and La Réunion and dominant ocean currents, indicated by lines and arrows. SEC South Equatorial Current, EMC East Madagascar Current, MC Mozambique Channel, $M C E$ Mozambique Channel Eddies, $A C$ Agulhas Current (Figure modified after Zinke et al. 2004a) 2004a, b). Thus, we assume that the seawater of this location represents large-scale oceanic properties, and that corals from this location archive large-scale climatic signals. The Porites sp. coral from La Réunion (hereafter RE) comes from the $10-12 \mathrm{~km}$ long fringing St. Gilles reef $\left(21^{\circ} \mathrm{S}\right.$ and $\left.55^{\circ} \mathrm{E}\right)$ at the western side of the island about $1 \mathrm{~km}$ off the coast. At the collection site the water depth is $12.3 \mathrm{~m}$. For both corals, bimonthly coral $\delta^{18} \mathrm{O}$ records were measured, January/February, March/April, etc. for IF and February/March, April/May, etc. for RE. IF represents the period of 1660-1994 and RE the period of 1832-1995, respectively. A detailed description of the analytical procedures and data processing can be found in Zinke et al. (2005) (IF) and Pfeiffer et al. (2004) (RE).

We investigate the coral stable isotopic composition $\delta^{18} \mathrm{O}$, which is a widely used proxy for temperature e.g. in ice cores and corals (Cole et al. 1993; Petit et al. 1999). For corals, $\delta^{18} \mathrm{O}$ is also a proxy for the oxygen isotopic composition of seawater $\left(\delta^{18} \mathrm{O}_{\mathrm{sw}}\right)$. This is related to seawater salinity (SSS) or oceanic advection, when upwelling and river runoff can be neglected. The relative importance of the SST and $\delta^{18} \mathrm{O}_{\mathrm{sw}}$ contribution to the coral $\delta^{18} \mathrm{O}$ record depends on the strength of the variation of the precipitation-evaporation balance (Craig and Gordon 1965). In oceanic settings with strong variation of this balance, coral $\delta^{18} \mathrm{O}$ predominantly represents the isotopic composition of seawater $\delta^{18} \mathrm{O}_{\text {sw }}$ (i.e. SSS) (Cole et al. 1993). In regions with a constant precipitation-evaporation balance, coral $\delta^{18} \mathrm{O}$ is mainly determined by SSTs (e.g. Zinke et al. 2004a, 2005). Since coral $\delta^{18} \mathrm{O}$ is a proxy for SST and SSS, their proportions to the coral variability potentially vary within the annual cycle, which would cause seasonally different climatic signals recorded by the corals. To account for this, we examine the annual mean as well as the bimonthly $\delta^{18} \mathrm{O}$ records of the two corals.

Instrumental data: sea surface temperature (SST) and sea level pressure (SLP)

Monthly SST anomalies for $5^{\circ}$ latitude by longitude boxes were obtained from the MOHSST5 data set based on the GOSTA data set of the U.K. Meteorological office (Parker et al. 1994; Reynolds and Smith 1994; Kaplan et al. 1997; Kaplan et al. 1998). There are no missing values due to data interpolation (Hurrell and Trenberth 1999). Monthly SLP data were obtained from the COADS data (Kaplan et al. 2000). The data were subjected to a reduced space optimal interpolation procedure and averaged on a $4^{\circ} \times 4^{\circ}$ grid. The SST and the SLP data set represent the period from 1856 up to present. The data cover nearly the entire northern hemisphere and the southern hemisphere up to $45^{\circ} \mathrm{S}$. The anomalies of the SST are based on the period between 1951 and 1980 . We calculated the annual mean anomalies. 


\section{Climatic and oceanic settings of the coral sites}

SST at the coral sites are influenced by the seasonal evolution of solar radiation and the strength of the southern Indian Ocean trade winds. According to a climatology starting in 1960 (Levitus and Boyer 1994; Conkright et al. 1994), SST maximum of more than $27^{\circ} \mathrm{C}$ occurs at Ifaty between December and March and minimum SST from July until September $\left(22.5^{\circ} \mathrm{C}\right)$. The salinity (SSS) varies between 34.9 psu in February and up to 35.4 psu in August-October. In La Réunion the SST varies between $23.0^{\circ} \mathrm{C}$ in August/ September and $27.5^{\circ} \mathrm{C}$ in February. The SSS reaches its maximum in November (35.2 psu) and its minimum in April (34.9 psu). The P-E balance is roughly similar for both locations and varies with the intensity of the trade winds, which are accompanied by periods with heavy rainfall in the boreal winter and only small precipitation rates in boreal summer. Therefore, the P-E balance varies between -50 and $-100 \mathrm{~mm} / \mathrm{month}$ in June-October, representing higher evaporation than precipitation, whereas in January-March precipitation dominates, leading to $\mathrm{P}-\mathrm{E}$ values between +50 and $+100 \mathrm{~mm} /$ month (Oberhuber 1988).

The oceanic circulation system near La Réunion is dominated by the westward flowing South Equatorial Current (SEC), which forms the northern branch of the southern Indian Ocean gyre (Fig. 1). The SEC is linked to the Indonesian throughflow, both transporting heat and freshwater from the equatorial Pacific to the southwestern Indian Ocean. After passing Mauritius and La Réunion the SEC splits into two branches off the east coast of Madagascar. One branch turns southward and feeds the AC. The other branch flows northward around the northern tip of Madagascar and partly turns southward, together with waters from the northern tropical Indian Ocean forming a train of large anticyclonic Mozambique Channel Eddies (MCE) that propagate southward. After passing the Mozambique Channel, the MCE and the southern branch of the SEC join to the southward flowing $\mathrm{AC}$, which is part of the warm surface flow within the global oceanic circulation system (DiMarco et al. 2002). Thus, the SEC directly influences seawater near La Réunion, whereas in Ifaty the SEC and the northern tropical Indian Ocean affect seawater composition (Zinke et al. 2004a). Wajsowicz and Schopf (2001) found indications that the Indonesian throughflow via the SEC affects evaporation over the southern Indian Ocean, which implies a link between Pacific Ocean climate and $\delta^{18} \mathrm{O}_{\mathrm{sw}}$ in areas influenced by the SEC (Wajsowicz 2002; DiMarco et al. 2002; Wajsowicz and Schopf 2001; Allan et al. 1995). This $\delta^{18} \mathrm{O}_{\mathrm{sw}}$ signal would be probably more striking in the RE coral than in IF coral, since the SEC directly influences only the RE location. These suggestions could be roughly confirmed with coral records. Pfeiffer et al. (2004) investigated the annual mean RE coral $\delta^{18} \mathrm{O}$ record and found spectral peaks on ENSO periods of 3-7 years and on periods of 30-35 years. However, although coral $\delta^{18} \mathrm{O}$ and SST at La Réunion are coherent at periods of 30-35 years, the sense of this relationship is of opposite sign as expected based on the known coral $\delta^{18} \mathrm{O}$-temperature relationship. Lighter mean isotopic values, which would be indicative of higher temperatures, correspond to periods of cooler SST (and vice versa) in the southwestern Indian Ocean. Therefore, the authors concluded that the isotopic composition of annual RE mainly represents $\delta^{18} \mathrm{O}_{\mathrm{sw}}$ and SSS, reflecting the transport of fresher waters from the central and eastern Indian Ocean and the Indonesian throughflow by the SEC. Thus, they inferred that the SEC underlies decadal variability. In contrast, Zinke et al. (2004a) found that on the whole the IF $\delta^{18} \mathrm{O}$ record represents regional SST: Ifaty coral $\delta^{18} \mathrm{O}$ is negatively correlated with regional SST, as expected, based on the known coral $\delta^{18} \mathrm{O}$-temperature relationship. Furthermore, coherency is found between boreal summer $\delta^{18} \mathrm{O}$ coral record and the regional SST on decadal and multidecadal time scales.

\section{Methods}

To isolate the main PDO frequencies, we apply a bandpassfilter to the coral, SST and SLP time series, suppressing all variance outside of the prescribed window (von Storch and Zwiers 1999). To do this we first removed the linear trends from the time series and determined the anomalies for the investigation period (1882-1993). Then we applied the bandpass-filter. According to Mantua and Hare (2002), the PDO is predominantly found for periods of lengths between 15 and 25 years. Thus we performed the filter for wave numbers between 4 and 7 . These wave numbers represent periods of 16-28 years for our time series length of 112 years. We do not consider the 50- to 70-year periods, which were also identified by Mantua and Hare as PDO periods, since they are not well represented in our time series.

Based on the bandpass-filtered data, we performed two approaches to identify the PDO patterns: one method used covariance maps between filtered coral and SST and SLP time series, respectively. The covariance $C(x, y)$ is calculated from:

$C(x, y)=\frac{1}{n} \sum_{i=1}^{n}\left(x_{i}-\bar{x}\right)\left(y_{i}-\bar{y}\right)$.

Here, the $x_{i}$ are the time series of the SST and SLP, respectively. The $y_{i}$ represent the coral record and $\bar{x}$ and $\bar{y}$ the corresponding temporal means. The second approach is based on EOF analysis (von Storch and Zwiers 1999). This approach is similar to that of Kaplan et al. (2000), who applied the EOF technique to global, annual SST and SLP 
Fig. 2 Original $\delta^{18} \mathrm{O}$ time series (\%o): a Ifaty: annual (black), March/April (red), July/Augusr (blue),

November/December (green); b La Réunion: annual (black), February/March (red), June/July (blue), October/November (green)
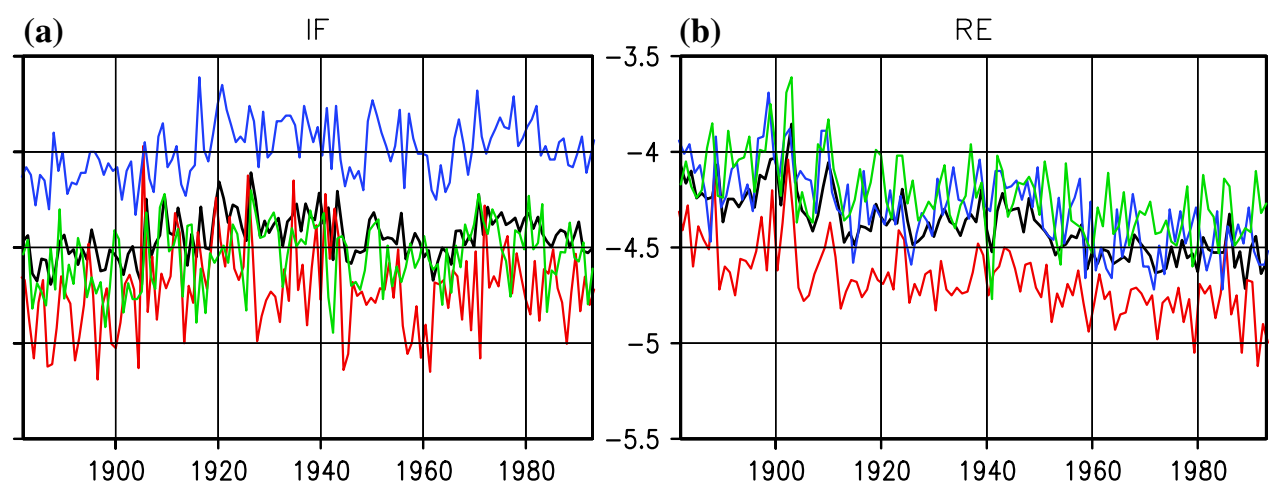

fields filtered with a 5-year running mean. The first leading mode in Kaplan et al. (2000) represents the long-term trend, which is removed in our analysis, since we use detrended data. Thus, the first EOF in our analysis represents the second EOF of Kaplan et al. (2000), identified as PDO. We performed the EOF analysis for the annual mean, detrended anomalies of the SST and the SLP, covering the areas of the Pacific and the Indian Ocean. Therefore, we account for the possibility of a link between both oceans in the PDO. The data were bandpassfiltered as described above. In order to account for the different definitions of the PDO, we calculated the EOFs for both, coupled and single SST and SLP fields. Thus the first approach (hereafter "coupled") explicitly prescribes the co-variability of the SST and SLP pattern time series, whereas the latter (hereafter "SST-only" and "SLP-only", respectively) does not. The procedure to obtain the coupled EOF is as follows: firstly the SST and SLP fields are normalized to unit standard deviation. Secondary the fields are merged to one field and the EOF procedure is applied. Afterwards the EOF patterns are separated again into a SST and SLP pattern. Finally the normalization is reversed.

The relationship between the corals and the PDO is examined by the filtered coral time series and the principal components of the first EOF (PC1).

\section{Results}

\section{Coral records}

In the following, we only refer to the annual mean and three bimonthly series of each coral. For the Ifaty coral the bimonthly series are the March/April, July/August and the November/December records, for the La Réunion coral the February/March, June/July and October/November series. These records are sufficient to demonstrate the most important properties of the corals with respect of the PDO. On average, IF annually varies between $-4.0 \%( \pm 0.14)$ and $-4.9 \%$ o $( \pm 0.15)$ and RE between $-4.0 \%$ o $( \pm 0.15)$ and $-4.7 \%$ o $( \pm 0.12)$, thus the intra-annual variation for $R E$ is slightly smaller than for IF. For IF the highest (lowest) values among the three selected bimonthly records occur in July/August (March/April), roughly corresponding with the seasons, when the temperatures are lowest (highest). For $\mathrm{RE}$ the lowest values are also found at the end of boreal winter (February/March), the magnitudes for June/July and October/November are similar (Fig. 2 and Table 1).

\section{PDO patterns}

The first EOF of SST-only (SLP-only) explains 41\% (39\%) of the total variance of the fields. Both patterns clearly reproduce the PDO patterns described by Kaplan et al. (2000) and others (Mantua et al. 1997; Tourre et al. 2001; Krishnan and Sugi 2003) (Fig. 3). The SST-only pattern is characterized by a large area of positive anomalies in the eastern Equatorial Pacific that extends up the North and South American coasts. There are also the typical coldwater tongues in the west Pacific around $30^{\circ} \mathrm{N}$ and $30^{\circ} \mathrm{S}$, flanking the positive equatorial SST anomalies. In the Indian Ocean a weak signal is found around Madagascar, i.e. the site of the corals used in this study. South of Madagascar, there are negative SST anomalies. Farther to the north are positive SST anomalies where La Réunion lies (Fig. 3a). The first EOF of SLP-only is dominated by a

Table 1 Coral $\delta^{18} \mathrm{O}$ records (per mill) and standard deviation (in brackets) used in this article

\begin{tabular}{lllllll}
\hline & Annual & Annual maximum & Annual minimum & March/April & July/August & November/December \\
\hline IF & $-4.43(0.11)$ & $-3.97(0.14)$ & $-4.86(0.15)$ & $-4.69(0.22)$ & $-3.97(0.14)$ & $-4.54(0.17)$ \\
\hline & Annual & Annual maximum & Annual minimum & February/March & June/July & October/November \\
\hline RE & $-4.38(0.11)$ & $-3.99(0.15)$ & $-4.70(0.12)$ & $-4.66(0.14)$ & $-4.29(0.16)$ & $-4.23(0.16)$ \\
\hline
\end{tabular}


Fig. 3 EOF pattern of the bandpass-filtered annual anomalies (1882-1993); a SST-only $\left(10^{-1} \mathrm{~K}\right)$ (contour increments: $-2,-1,-0.5$, $-0.25,0.25,0.5,1,2)$; b SLP-only $\left(10^{-1} \mathrm{hPa}\right)$ (contour increments: $-4,-3,-2,-1,1)$

Fig. 4 Same as Fig. 3 for coupled SST and SLP fields
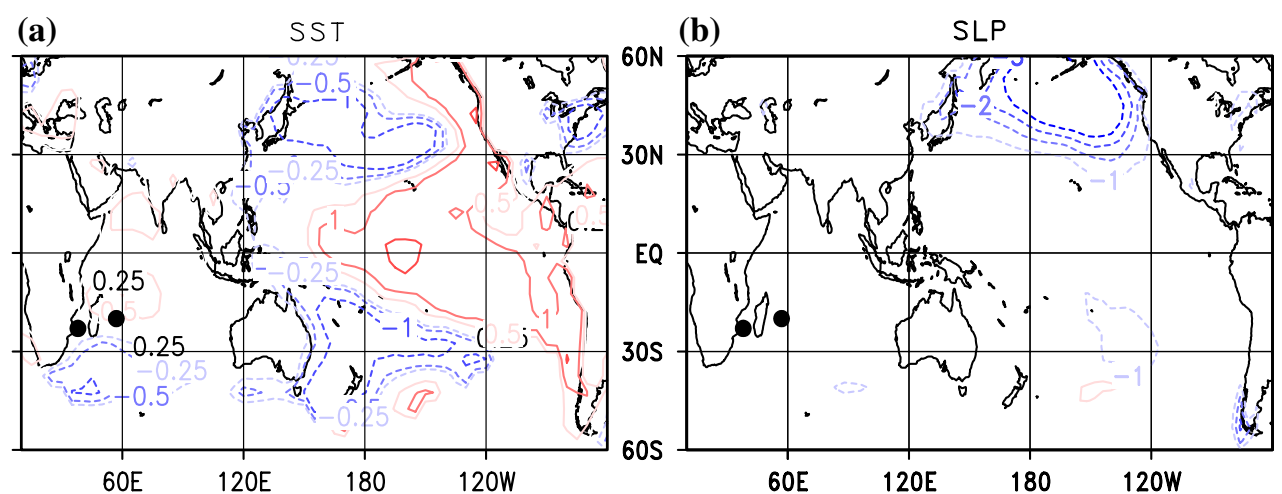

(a)
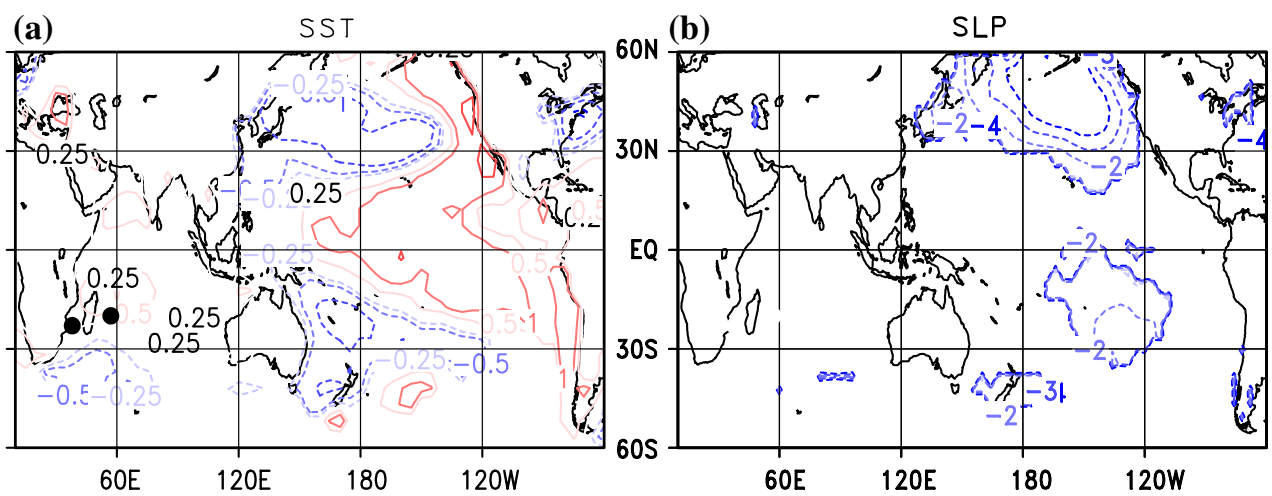

strong depression around the Aleutians in the North Pacific. Small negative anomalies are obtained south of the Equator. No signal is found in the Indian Ocean. This contrasts with Kaplan et al. (2000) who found weak positive SLP anomalies especially in the West Indian Ocean (Fig. 3b). The patterns of the coupled EOF (35\% explained variance for the coupled SST and SLP field), shown in Fig. 4, match well the EOFs that are obtained utilizing the single fields (Fig. 3). This indicates that both definitions of the PDO yield widely the same result. The only remarkable difference is obtained for the SLP pattern in the South Pacific. Here, the coupled pattern shows a slight depression, almost absent in the SLP-only pattern. Figure 5

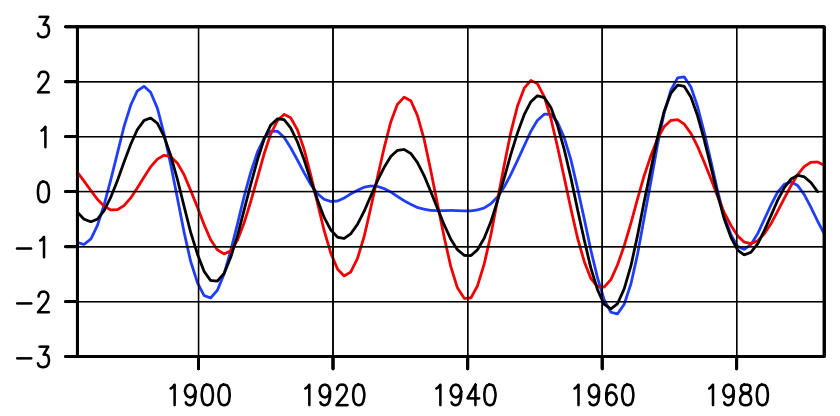

Fig 5 PC1 of bandpass-filtered SST-only (blue), SLP-only (red) and coupled SST/SLP fields (black) shows the PC1 of the SST-only, the SLP-only and the coupled SST/SLP fields. Although we do not prescribe the temporal coherency between SST-only and the SLP-only, the PC1 widely co-vary, except for the period from 1920 to 1945, when the amplitude of SST-only PC1 is around zero. The SLP-only PC1, however, shows a uniform behavior for the entire period with increasing amplitudes until the 1950s, followed by decreasing amplitudes. The correlation between the two PC1 is 0.72 . Due to the filter procedure, there is high auto-correlation in the two time series, which greatly reduces the degrees of freedom $(n)$ in assessing the significance levels of the correlations, here $n=5$. Taking this into account, the correlation is statistically significant at the $90 \%$ level (Dawdy and Matalas 1964; Leith 1973). PC1 of the coupled EOF regularly varies with decreasing amplitudes until the middle of the last century and increasing thereafter, on the whole widely similar with the SST-only and SLP-only PC1. Thus, we have shown that both approaches deriving the PDO-patterns on the whole reflect formerly described PDO characteristics.

\section{Covariance patterns}

For both corals we performed the covariance procedure with the instrumental annual mean SST and SLP series for 
the annual mean as well as for bimonthly time series. All data were filtered before as described above. The covariance patterns between the RE $\delta^{18} \mathrm{O}$ coral time series and SST (Fig. 6, left panel) shows the seasonally varying appearance of the SST-PDO pattern. It appears in February/March and becomes more pronounced in June/July, whereas for the rest of the year the PDO pattern vanishes. The June/July map shows statistically significant values mainly in the Equatorial Pacific but also in the North Pacific (at the $90 \%$ level, shaded areas). The corresponding pattern for the annual mean coral $\delta^{18} \mathrm{O}$ also shows a PDO structure with positive anomalies around the Equatorial Pacific. However, this pattern is less pronounced than the June/July pattern and shows less correspondence with our reference SST-PDO pattern in Figs. 3a, 4a. North of La Réunion covariance is positive and significant in June/July. The covariance patterns of the RE coral series with SLP (Fig. 6, right panel) show low pressure in February/March and June/July near the Aleutians; but the correlation is not statistically significant. In October/November, there is no PDO signal. For the annual mean time series a PDO pattern appears, but also no significant correlation values occur.

The PDO signal of IF is opposite to that of La Réunion with IF showing a stronger SLP PDO than SST PDO (Fig. 7, note that the values are multiplied by -1 ).

The SST PDO signal is seasonally dependent for IF. It clearly evolves in boreal summer (July/August) with small
Fig. 6 Covariance between bandpass-filtered annual instrumental SST and SLP and bandpass-filtered La Réunion coral $\delta^{18} \mathrm{O}$ for a SST and February/March $\delta^{18} \mathrm{O}$, b SLP and February/March $\delta^{18} \mathrm{O}$, c SST and June/July $\delta^{18} \mathrm{O}$, d SLP and June/July $\delta^{18} \mathrm{O}$, e SST and October/November $\delta^{18} \mathrm{O}, \mathbf{f}$ SLP and October/ November $\delta^{18} \mathrm{O}$, g SST and annual $\delta^{18} \mathrm{O}$, h SLP and annual $\delta^{18} \mathrm{O}$. Contour intervals for SST covariance $\left(10^{-3} \mathrm{~K} \% \mathrm{~s}\right)$ are -4 , $-3,-2,-1,1,2,3,4$, for SLP covariance $\left(10^{-2} \mathrm{hPa} \%\right)$ are $-2,-1,-0.5,-0.25,0.25$. Shaded areas are significant at 90\% confidence level after adjusting degrees of freedom (a)

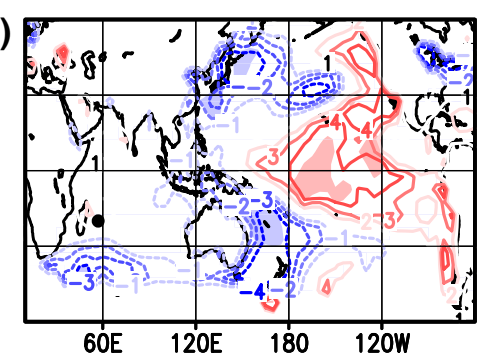

(c)

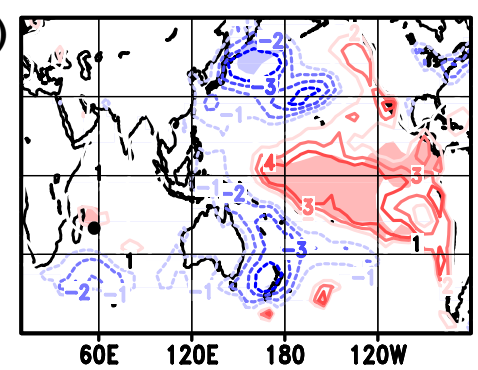

(e)

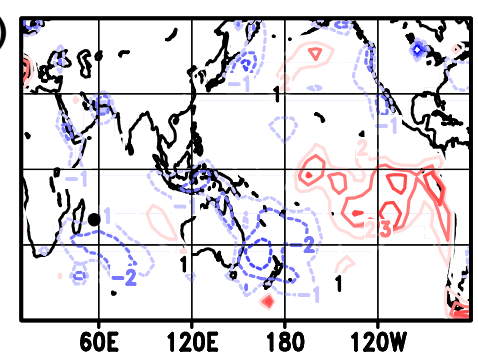

(g)

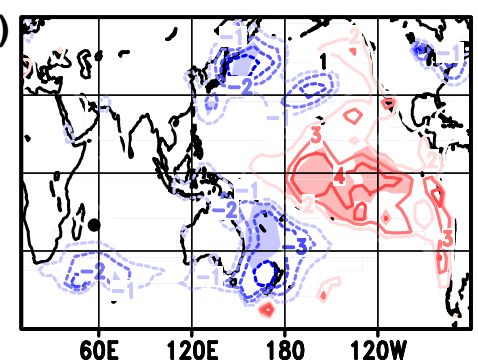

SLP

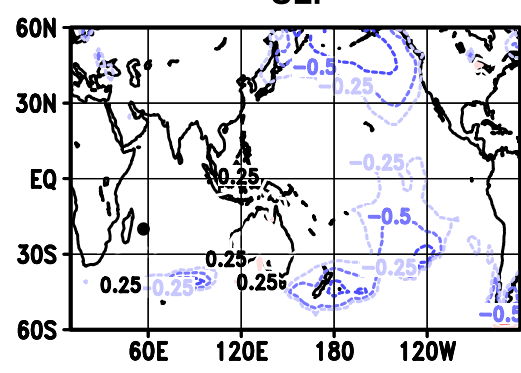

(b)

Feb./March

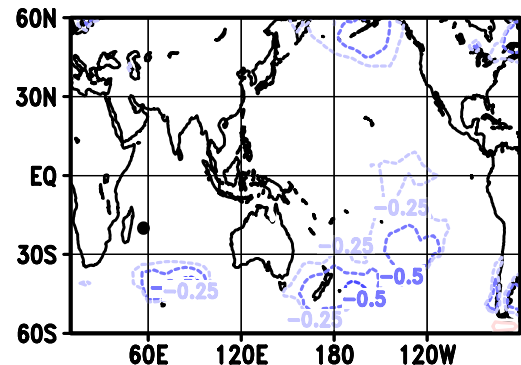

(d)

June/July

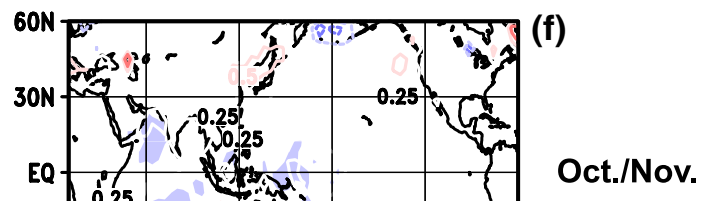

605
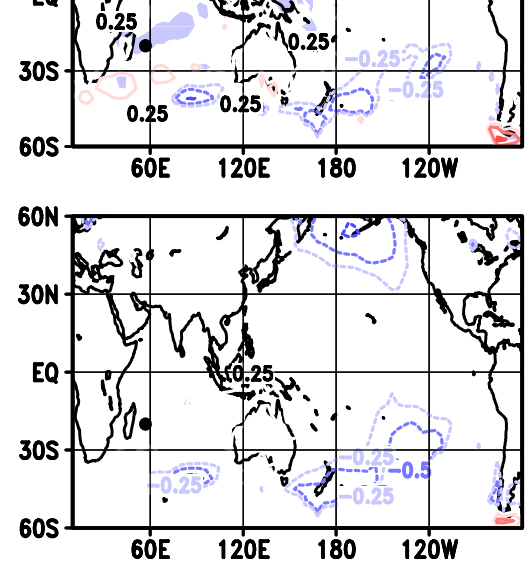

(h)

Annual 
Fig. 7 Covariance between bandpass-filtered annual instrumental SST and SLP and bandpass-filtered Ifaty coral $\delta^{18} \mathrm{O}$ for a SST and March/April $\delta^{18} \mathrm{O}$, b SLP and March/April $\delta^{18} \mathrm{O}$, c SST and July/August $\delta^{18} \mathrm{O}$, d SLP and July/August $\delta^{18} \mathrm{O}$, e SST and November/ December $\delta^{18} \mathrm{O}$, f SLP and November/December $\delta^{18} \mathrm{O}$, g SST and annual $\delta^{18} \mathrm{O}$, h SLP and annual $\delta^{18} \mathrm{O}$. Contour intervals for SST covariance $\left(10^{-3} \mathrm{~K} \%\right.$ ) are $-4,-3,-2$, $-1,1,2,3,4$, for SLP covariance $\left(10^{-2} \mathrm{hPa} \% \mathrm{o}\right)-2$, $-1,-0.5,-0.25,0.25$. Shaded areas are significant at $90 \%$ confidence level after adjusting degrees of freedom;

(scaled by -1 )
SST

(a)

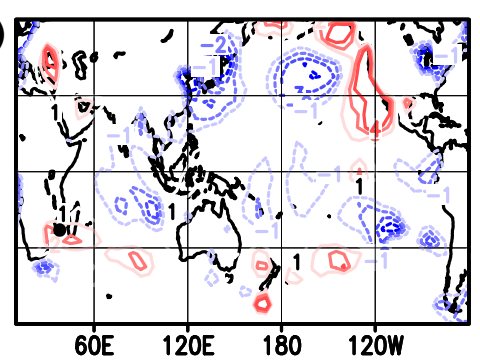

(c)

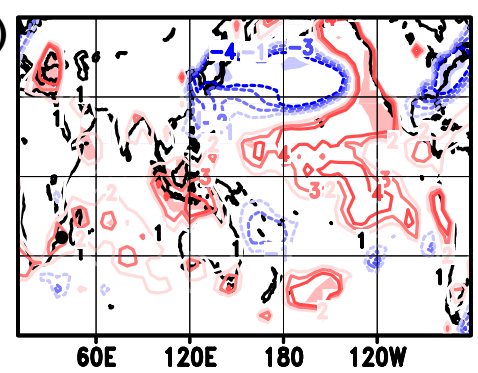

(e)

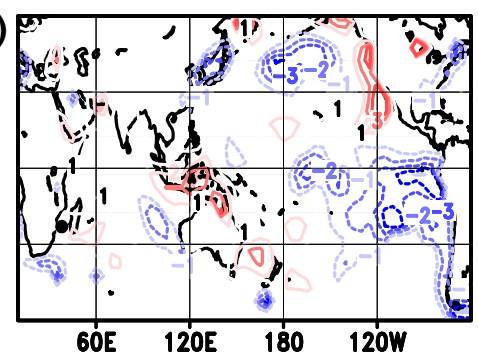

(g)

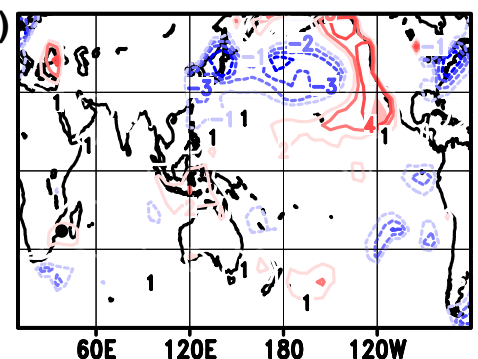

SLP
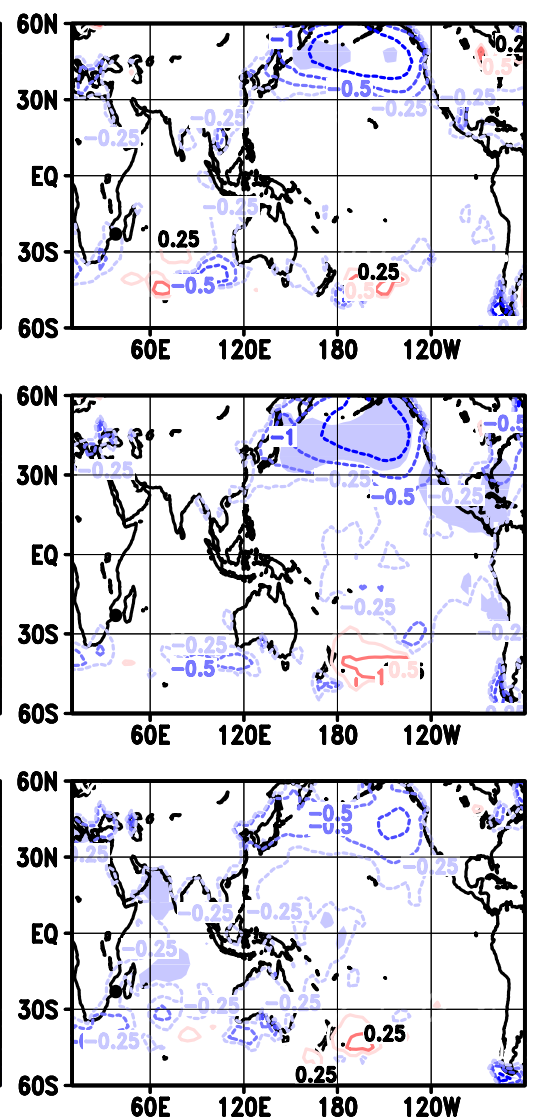

(f)

Nov./Dec.

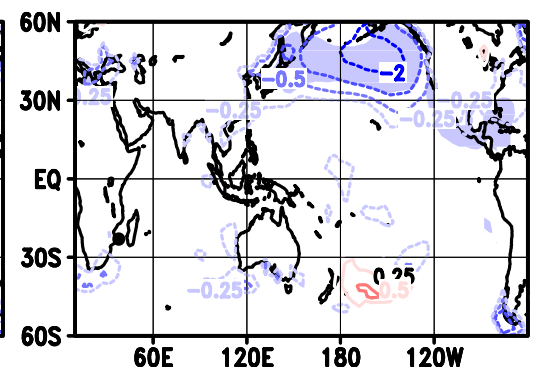

(h)

Annual (b)

March/April

(d)

July/August areas, where the correlation is significant. The strongest fingerprint is found in the midlatitude Pacific and less pronounced in the tropics, which is a main characteristic of the PDO (Mantua and Hare 2002; Linsley et al. 2004). The pattern has completely regressed in November/December. Consequently, the SST pattern obtained with the annual series only weakly represents the PDO pattern (Fig. 7g). The main SLP-PDO characteristic however, i.e. the lowpressure area near the Aleutians, is evident the whole year at IF, with the strongest structure in July/August. For these months, the correlation is also statistically significant in the North Pacific. The secondary PDO characteristic, i.e. weak negative anomalies south of the Equatorial Pacific is also found, especially in July/August. Because of the seasonally less varying SLP PDO signal, the annual map also shows the PDO structure (Fig. 7h).

A common technique to strengthen climatic signals in proxy data is the combination of several proxies (Mann 2002; Crueger et al. 2006; Pfeiffer and Dullo 2006; Pfeiffer et al. 2006). This reduces the noise and not climate related local influences and enhances the climatic information common amongst the different sites. Thus, we also tested a combination of the two coral time series, which both contained significant PDO signals. The greatest improvement, i.e. the highest correlation with the coupled PDO PC1 (see "Principal components") is obtained with a combination of the filtered series of RE (June/July) and the IF (July/August). This series has been established by 
calculating the mean of both records, multiplying IF with -1 (to account for the negative (positive) correlation of IF (RE) with SST/SLP PDO). The covariance map between this combined series with the SST (Fig. 8a) is very similar to our reference PDO patterns-(Figs. 3a, 4a). Slight improvements compared with the patterns obtained with RE (June/July) (Fig. 6c) are achieved in the eastern Pacific area with warm SST, however, at the cost of a less pronounced cold flank in the western Pacific around $30^{\circ} \mathrm{S}$. The SLP covariance pattern (Fig. 8b) shows both the strong North Pacific low and a slight depression in the South Pacific, thus corresponding with the SLP-PDO pattern obtained for the coupled fields (Fig. 4b).

\section{Principal components}

In order to further prove that the PDO and the coral records co-vary, we relate the filtered coral time series for IF (July/ August), RE (June/July) and the combined record to the PC1 of the single and coupled SST and SLP, respectively (Fig. 9 and Table 2). In Fig. 9 the dashed lines indicate the coral records, while the solid lines represent the PC1. The combined IF/RE record obviously co-varies best with PC1 of the coupled SST/SLP PDO fields, especially until around 1960, when phase and amplitude coincide. Remarkable is the correspondence from 1920 to 1940 , when SST-only and SLP-only are out of phase. After 1960, the phases are slightly shifted and the combined coral record underestimates the coupled PDO amplitude. For these series the correlation is $r=0.8(n=5$; significant at the $90 \%$ level). Figure 9 also reveals that IF (July/August) matches well the SLP-only PC1 $(r=0.85)$. Except the first and last 20 years both curves nearly totally fit, i.e. not only the phase, but also the amplitude. A similar result is found for RE (June/July) and SST-only $(r=0.7)$ : Especially in the first half of the investigated period, both curves coincide, in the second half the phases also correspond, however, the amplitudes do not. Remarkable is that, especially from around 1920-1940, the period, when SST and SLP PC1 are out of phase, one coral (IF) widely follows SST-only, the other (RE) follows SLP-only and the combined IF/RE record the coupled PDO series.

\section{Discussion}

Coral $\delta^{18} \mathrm{O}$ records from two sites of the western Indian Ocean show pronounced PDO-like signals, for the SSTonly, the SLP-only and the coupled SST/SLP PDO. This confirms previous suggestions of a PDO fingerprint in the Indian Ocean (e.g. Reason and Rouault 2002; Krishnan and Sugi 2003). The coral time series of boreal summer months (June-August) show the strongest signals, whereas other seasonal or annual mean series on the whole show weaker signals. The corals from La Réunion and the southwest Madagascar differently record the strength of SST-only and the SLP-only PDO signals. While for IF (July/August) the SLP-only signal is more dominant, RE (June/July) better records the SST-only signal. This could be due to the different sample locations, around $1,000 \mathrm{~km}$ apart and separated by Madagascar, and probably subjected to different climate impacts. On the other hand, we assume that $\mathrm{IF}(J u l y /$ August) and RE (June/July) represent different physical properties on the PDO timescale. IF (July/August) is suggested to represent SST, because the correlation with regional SST is negative $(r=-0.5)$, which is expected, provided that the $\delta^{18} \mathrm{O}$ represents the SST. We are aware of the fact that we relate seasonal $\delta^{18} \mathrm{O}$ against annual SST. However, since SSTs show high monthly auto-correlation $(r=0.84$ between unfiltered annual and July/August SST at IF), we assume that the seasonal $\delta^{18} \mathrm{O}$ also reflects the annual SST. The determining parameter of the RE(June/ July) $\delta^{18} \mathrm{O}$ on the PDO timescale is obviously not SST, since the correlation of SST and coral $\delta^{18} \mathrm{O}$ is of opposite sign as expected based on the coral $\delta^{18} \mathrm{O}-\mathrm{SST}$ relationship at the PDO-frequencies. Therefore, we conclude that
Fig. 8 Covariance between bandpass-filtered combined $\mathrm{IF}($ July/August)/RE(June/July) series and annual instrumental a SST $\left(10^{-3} \mathrm{~K} \%\right)$. Contour increments: $-4,-3,-2,-1,1$, 2, 3, 4 and b SLP $\left(10^{-2} \mathrm{hPa}\right.$ $\%$ ). Contour increments: -2 , $-1,-0.5,-0.25,0.25$. Shaded areas are significant at $90 \%$ confidence level after adjusting degrees of freedom
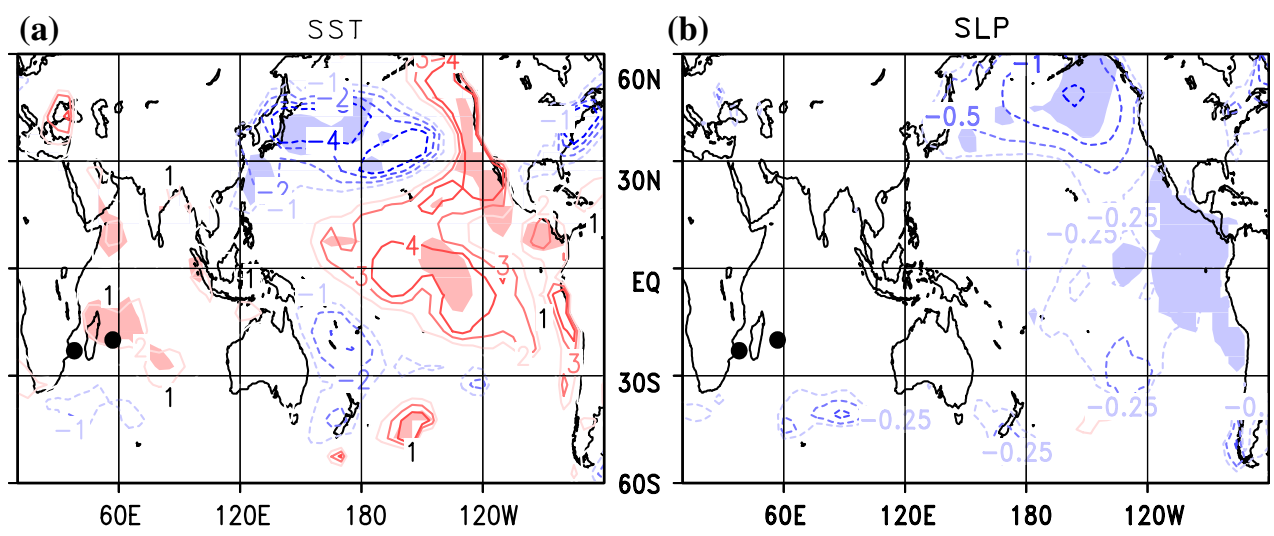


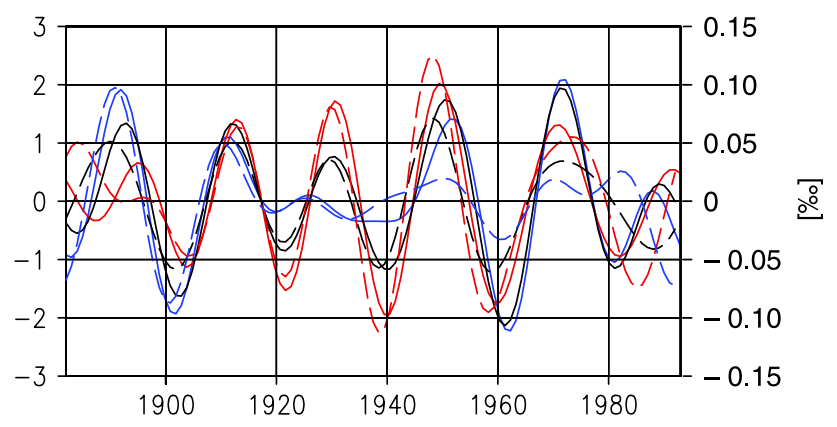

Fig. 9 PC1 of bandpass-filtered SST-only (solid blue), SLP-only (solid red), coupled SST/SLP (solid black), bandpass-filtered RE (June/July) (dashed blue), IF(July/August) (dashed red, scaled by -1) and combined record of $\mathrm{RE}(\mathrm{June} / \mathrm{July}) / \mathrm{IF}$ (July/August) (dashed black)

Table 2 Correlation between bandpass-filtered $\delta^{18} \mathrm{O}$ records and PC1 of bandpass-filtered SST, SLP and coupled SST/SLP

\begin{tabular}{lccc}
\hline & SST-only PDO & SLP-only PDO & Coupled PDO \\
\hline IF (July/August) & $-0.47 *$ & -0.85 & -0.71 \\
RE (June/July) & 0.7 & $0.2^{*}$ & $0.52^{*}$ \\
Combined IF/RE & 0.71 & 0.76 & 0.8
\end{tabular}

All values are significant at the $90 \%$ level, except those, marked by an asterisk

$\delta^{18} \mathrm{O}_{\text {sw }}$ dominates the $\delta^{18} \mathrm{O}$ of RE (June/July). Furthermore, we suppose that $\delta^{18} \mathrm{O}_{\mathrm{sw}}$ is not related to the hydrological cycle, since the P-E ratios at the IF and RE locations are similar and IF $\delta^{18} \mathrm{O}$ is not driven by $\delta^{18} \mathrm{O}_{\mathrm{sw}}$ (Oberhuber 1988). Therefore, advection remains a probable reason for $\mathrm{RE}-\delta^{18} \mathrm{O}_{\mathrm{sw}}$ variability, which at this location is probably related to the SEC and the Indonesian Throughflow. Thus, we follow Pfeiffer et al. (2004), who found that the annual $\mathrm{RE} \delta^{18} \mathrm{O}$ coral record is dominated by $\delta^{18} \mathrm{O}_{\mathrm{sw}}$ superimposing the SST signal. Furthermore they suggested that the $\delta^{18} \mathrm{O}_{\mathrm{sw}}$ varies with the strength of the SEC and the Indonesian Throughflow (see Fig. 1 and "Climatic and oceanic settings of the coral sites"). Thus, summarized, we assume that the coral $\delta^{18} \mathrm{O}$ represents SST in IF and $\delta^{18} \mathrm{O}_{\mathrm{sw}}$ in RE on the PDO time scale.

Our approach to separately identify SST- and SLP-signals shows that IF better records the SLP PDO variability, whereas RE better varies with SST PDO. This indicates that either the two coral locations are subject to slightly different climatic influences (see above), or it means that $\delta^{18} \mathrm{O}$ better records the remote SST PDO fingerprint via the SEC advection, while the SST in Ifaty better represents the remote SLP PDO signal. This points to differences between SST and SLP PDO variability, which should be confirmed and examined further utilizing additional data sources. Especially the flow through the Mozambique Channel with the MCE and their relationship to SLP PDO should be investigated. Furthermore, special emphasis should be laid to the decadal variability of the SEC and the Indonesian Throughflow with respect to SST and SLP PDO.

Our results confirm that it is a reasonable approach to relate seasonal proxy data to annual mean climatic data. This has previously been found by Kuhnert et al. (2005), who linked October-December means of $\mathrm{Sr} / \mathrm{Ca}$ of a coral from Bermuda to the North Atlantic Oscillation Index. Utilizing seasonal proxy data is reasonable, when climate signals only seasonally emerge in the proxy data, either due to seasonally varying noise proportions or due to physical reasons, for example because of seasonally varying representativeness of the proxy. A further improvement of the coupled SST/ SLP PDO signatures could be obtained with the combination of bimonthly values of IF and RE, whereby IF with an opposite sign as RE. This intuitively unreasonable combination is meaningful, taking into account our suggestions that both corals represent different parameters. Whereas IF is supposed to represent regional SST, we found indications that RE represents $\delta^{18} \mathrm{O}_{\mathrm{sw}}$. The combined coral record more accentuates the characteristics of the PDO (Fig. 8), which is also confirmed by the courses of the combined record and the coupled PDO PC1 (Fig. 9). However, a combination of several proxy records is only meaningful after proving the extent to what the climatic signal is evident in each record (Crueger et al. 2006). Combination with other bimonthly or with the annual mean records did not improve the results. The correlation value is $r=0.76(r=0.71)$ between the combined coral record and PC1 of the SLP-only (SST-only) PDO, between the combined coral series and the coupled SST/SLP PC1 $r=0.8$. Thus, $64 \%$ of the variance of the coupled SST/SLP PDO variance is explained by the combined time series. This is a strong improvement compared to the single time series, for which $27 \%$ [RE (June/July)] and $50 \%$ [IF (July-August)] are obtained (see Table 2).

\section{Conclusions}

The aim of this study is to detect PDO signals in coral records from the Indian Ocean. For that reason, we investigate periods from 16 to 28 years, thus selecting PDO frequencies reported in the literature. Based on this PDO definition, we draw the following conclusions:

- $\delta^{18} \mathrm{O}$ in corals from the western Indian Ocean are significantly related to the SST-only and SLP-only patterns of the PDO. The signal of the coupled SST/ SLP PDO is even more pronounced in the combined IF/ RE record. We thus confirmed the previously assumed link between Pacific and Indian Ocean decadal climate variability.

- Covariability of SST-only and SLP-only PDO is temporally disturbed. The corals from the two sites 
also record this, i.e. IF predominantly follows the SLP-only and RE the SST-only PDO. Since IF is affected by the flow through the Mozambique Channel and RE by the SEC, we suggest that there is a relationship between the deviations between SST-only and SLP-only on the one hand and differences between the flow through the Mozambique Channel and the SEC on the other hand. This should be confirmed by further examinations of the single and coupled SST/SLP PDO series and their relationship with interdecadal variability of the flow through the Mozambique Channel and the SEC.

- We could strengthen the PDO signals by utilizing bimonthly resolved coral data. Boreal summer $\delta^{18} \mathrm{O}$ records better archive the PDO signals than annual or other seasonal mean values. Therefore, we conclude that seasonally resolved proxy data potentially better record climate signals than annual means. Furthermore, we found indications that the two corals investigated here represent different parameters. While IF (July/ August) represents SST, RE (June/July) is supposed to reflect $\delta^{18} \mathrm{O}_{\mathrm{sw}}$.

- In order to further increase paleoclimatic evidence of the PDO, corals should be sampled preferably in the central equatorial Pacific (Kiritimati, Palmyra Atoll) and the southwest Pacific (New-Caledonia, the Norfolk-Islands and Fidschi). To further strengthen the remote link between PDO and the Indian Ocean new corals could be exploited from the Arabian Sea, the region south of Madagascar and north or northeast of Madagascar and La Réunion, respectively. Investigating a set of proxy data representing the key areas of the PDO (e.g. tree rings form the north Pacific coastal regions), could also help to understand the underlying physical processes of the PDO and the remote link with the Indian Ocean.

Acknowledgments Kaplan SST V2 and SLP data provided by the NOAA/OAR/ESRL PSD, Boulder, Colorado, USA, from their Web site at http://www.cdc.noaa.gov/. This research was financed by the European Community under the ENSEMBLES project. We would like to thank the TESTREEF-group for the drilling of the coral cores between 1994 and 1996. We especially thank B. Thomassin for his enthusiastic support. We thank H. Erlenkeuser (Leibniz Laboratory, University Kiel) and M. Joachimski (University Erlangen) for carrying out part of the oxygen isotope analysis. This research was supported by the German Science Foundation (Leibniz Award to Prof. Wolf-Christian Dullo and SFB 460, project B1) and the European Community's Human Potential Programme under contract HPRNCT-2002-00221 (STOPFEN). We are grateful to Janice Lough for her valuable comments, helping to improve our article.

Open Access This article is distributed under the terms of the Creative Commons Attribution Noncommercial License which permits any noncommercial use, distribution, and reproduction in any medium, provided the original author(s) and source are credited.

\section{References}

Allan RJ, Lindesay JA, Reason CJR (1995) Multidecadal variability in the climate system over the Indian Ocean region during the austral summer. J Clim 8(7):1853-1873

Barlow M, Nigam S, Berbery EH (2001) ENSO, Pacific decadal variability, and US summertime precipitation, drought and stream flow. J Clim 14(9):2105-2128

Cole JE, Fairbanks RG, Shen GT (1993) Recent variability in the Southern Oscillation: isotopic results from a Tarawa Atoll Coral. Science 260:1790-1793

Conkright ME, Levitus S, Boyer TP (1994) World Ocean atlas, 1: nutrients. NOAA atlas NESDIS 1. US Department of Commerce, Washington, $\mathrm{p} 150$

Craig H, Gordon LI (1965) Deuterium and oxygen 18 variations in the ocean and the marine atmosphere. In: Tongiorgi E (ed) Stable isotopes in oceanographic studies and paleotemperatures. Cons Naz di Rech, Spoleto, pp 9-130

Crueger T, Kuhnert H, Pätzold J, Zorita E (2006) Calibrations of Bermuda corals against large-scale sea surface temperature and sea level pressure pattern time series and implications for climate reconstructions. J Geophys Res 111:D23103. doi:10.1029/ 2005JD006903

D'Arrigo R, Wilson R (2006) On the Asian expression of the PDO. Int J Clim 26(12):1607-1617

D'Arrigo R, Wilson R, Deser C, Wiles G, Cook E, Villalba R, Tudhope A, Cole J, Linsley B (2005) Tropical-North Pacific climate linkages over the past four centuries. J Clim 18(24): $5253-5265$

Dawdy DR, Matalas NC (1964) Statistical and probability analysis of hydrologic data, part III: analysis of variance, covariance and time-series. In: Chow VT (ed) Handbook of applied hydrology. A compendium of water-resources technology. McGraw-Hill, New York, pp 8.68-8.90

Deser C, Phillips AS, Hurrell JW (2004) Pacific interdecadal climate variability: linkages between the tropics, the North Pacific during boreal winter since 1900. J Clim 17(16):3109-3124

DiMarco SF, Chapman P, Nowlin WD, Hacker P, Donohue K, Luther M, Johnson GC, Toole J (2002) Volume transport and property distributions of the Mozambique channel. Deep Sea Res II 49:1481-1511

Dominiak S, Terray P (2005) Improvement of ENSO prediction using a linear regression model with a southern Indian Ocean sea surface temperature predictor. Geophys Res Lett 32:L18702. doi:10.1029/2005GL023153

Dunbar RB, Wellington GM, Colgan MW, Glynn PW (1994) Eastern Pacific sea surface temperature since 1600 A.D.: the $\delta 180$ record or climate variability in Galapagos corals. Paleoceanography 9(2):291-316

Evans MN, Cane MA, Schrag DP, Kaplan A, Linsley BK, Villalba R, Wellington GM (2001) Support for tropically-driven Pacific decadal variability based on paleoproxy evidence. Geophys Res Lett 28(19):3689-3692. doi:10.1029/2001GL013223

Godfrey JS (1996) The effect of the Indonesian throughflow on ocean circulation and heat exchange with the atmosphere: a review. J Geophys Res 101(C5):12,217-12,238

Gordon AL, McClean JL (1999) Thermohaline stratification of the Indonesian seas: model and observations. J Phys Oceanogr 29(2):198-216

Hurrell JW, Trenberth KE (1999) Global sea surface temperature analysis: multiple problems and their implications for climate analysis, modeling and reanalysis. Bull Am Meteorol Soc 80: 2661-2678

Kaplan A, Kushnir Y, Cane MA, Blumenthal MB (1997) Reduced space optimal analysis for historical data sets: 136 years of 
Atlantic sea surface temperatures. J Geophys Res 102:27,83527,860

Kaplan A, Cane M, Kushnir Y, Clement A, Blumenthal M, Rajagopalan B (1998) Analyses of global sea surface temperature 1856-1991. J Geophys Res 103:18,567-18,589

Kaplan A, Kushnir Y, Cane MA (2000) Reduced space optimal interpolation of historical marine sea level pressure. J Clim 13:2987-3002

Krishnan R, Sugi M (2003) Pacific decadal oscillation and variability of the Indian summer monsoon rainfall. Clim Dyn 21:233-242. doi:10.1007/s00382-003-0330-8

Kuhnert H, Crüger T, Pätzold J (2005) NAO signature in a Bermuda coral $\mathrm{Sr} / \mathrm{Ca}$ record. Geochem Geophys Geosys 6:Q04004. doi: 10.1029/2004GC000786

Leith CE (1973) The standard error of time-averaged estimates of climatic means. J Appl Meteorol 21:1066-1069

Levitus S, Boyer TP (1994) World Ocean atlas 1994. US Department of Commerce, Washington, p 99

Linsley BK, Wellington GM, Schrag DP, Ren L, Salinger MJ, Tudhope AW (2004) Geochemical evidence from corals for changes in the amplitude and spatial pattern of South Pacific interdecadal climate variability over the last 300 years. Clim Dyn 22:1-11

Mann ME (2002) The values of multiple proxies. Science 297:14811482

Mantua NJ, Hare SR (2002) The Pacific decadal oscillation. J Oceanogr 58:35-44

Mantua NJ, Hare SR, Zhang Y, Wallace JM, Francis RC (1997) A Pacific interdecadal climate oscillation with impacts on salmon production. Bull Am Meteorol Soc 78:1069-1079

Minobe S (1999) Resonance in bidecadal and pentadecadal climate oscillations over the North Pacific: role in climatic regime shifts. Geophys Res Lett 26(7):855-858. doi:10.1029/1999GL900119

Minobe S (2000) Spatio-temporal structure of the pentadecadal variability over the North Pacific. Prog Oceanogr 47:381-408

Nakamura H, Lin G, Yamagata T (1997) Decadal climate variability in the North Pacific during the recent decades. Bull Am Meteorol Soc 78:2215-2225

Oberhuber JM (1988) An atlas based on 'COADS' dataset: the budgets of heat and turbulent kinetic energy at the surface of the global ocean. Max Planck Institute for Meteorology, Hamburg, p 28

Parker DE, Jones PD, Folland CK, Bevan A (1994) Interdecadal changes of surface temperature since the late nineteenth century. J Geophys Res 99:14,373-14,399

Petit JR, Jouzel J, Raynaud D, Barkov NI, Barnola J-M, Basile I, Bender M, Chappellaz J, Davis M, Delaygue G, Delmotte M, Kotlyakov VM, Legrand M, Lipenkov VY, Lorius C, Pépin L, Ritz C, Saltzman E, Stievenard M (1999) Climate and atmospheric history of the past 420,000 years from the Vostok ice core. Antarct Nat 399:429-436. doi:10.1038/20859

Pfeiffer M, Dullo W-C (2006) Monsoon-induced cooling of the western equatorial Indian Ocean as recorded in coral oxygen isotope records from the Seychelles covering the period 1840 1994 AD. Quat Sci Rev 25:993-1009
Pfeiffer M, Timm O, Dullo W-C, Podlech S (2004) Oceanic forcing of interannual and multidecadal climate variability in the southwestern Indian Ocean: evidence from a 160 year coral isotopic record (La Réunion, 55E, 21S). Paleoceanography 19:PA4006. doi:10.1029/2003PA000964

Pfeiffer M, Timm O, Dullo W-C, Garbe-Schoenberg D (2006) Paired coral $\mathrm{Sr} / \mathrm{Ca}$ and $\delta^{18} \mathrm{O}$ records from the Chagos Archipelago: late twentieth century warming affects rainfall variability in the tropical Indian Ocean. Geology 34(12):1069-1072

Reason CJC, Rouault M (2002) ENSO-like decadal variability and South African rainfall. Geophys Res Lett 29(13):1638. doi:10.1029/2002GL014663

Reynolds RW, Smith TM (1994) Improved global sea surface temperature analysis using optimum interpolation. J Clim 7: 929-948

Tourre YM, Rajagopalan B, Kushnir Y, Barlow M, White WB (2001) Patterns of coherent decadal and interdecadal climate signals in the Pacific basin during the 20th century. Geophys Res Lett 28(10):2069-2072. doi:10.1029/2000GL012780

von Storch H, Zwiers FW (1999) Statistical analysis in climate research. Cambridge University Press, London, ISBN 0521 $450713,494 \mathrm{pp}$

Wajsowicz RC (2002) Air-sea interaction over the Indian Ocean due to variations in the Indonesian throughflow. Clim Dyn 18 : $437-453$

Wajsowicz RC, Schopf PS (2001) Oceanic influences on the seasonal cycle in evaporation rate over the Indian Ocean. J Clim 14: $1199-1226$

Webster PJ, Magana VO, Palmer TN, Shukla J, Thomas RA, Yanai M, Yasunari T (1998) Monsoons: processes, predictability, and the prospects for prediction. J Geophys Res 103(C7):14,45114,510

Webster PJ, Moore AM, Loschnigg JP, Leben RR (1999) Coupled ocean-atmosphere dynamics in the Indian Ocean during 19971998. Nature 401:356-359

Zhang Y, Wallace JM, Battisti DS (1997) ENSO-like interdecadal variability. J Clim 10:1004-1020

Zinke J, Dullo W-C, Heiss GA, Eisenhauer A (2004a) ENSO and subtropical dipole variability is recorded in a coral record off southwest Madagascar for the period 1659 to 1995. Earth Planet Sci Lett 228(1-2):177-197

Zinke J, von Storch H, Mueller B, Zorita E, Rein B, Mieding B, Miller H, Luecke A, Schleser GH, Schwab M, Negendank JFW, Kienerl U, Gonzalez-Rouco J-F, Dullo W-C, Eisenhauer A, KIHZ-Consortium (2004b) Evidence for the climate during the late maunder minimum from proxy data and model simulations available within KIHZ. In: von Storch H, Raschke E, Floeser G (eds) The climate in historical times-towards a synthesis of Holocene proxy data and climate models. Springer, Berlin, pp 397-414

Zinke J, Pfeiffer M, Timm O, Dullo W-C, Davies GR (2005) Atmosphere-Ocean dynamics in the western Indian Ocean recorded in corals. Philos Trans R Soc A 363:121-142 